\section{OS OBJETOS ESPORTIVOS NA CULTURA INFANTIL: DIMENSÕES MATERIAIS E REPRESENTAÇÕES}

\author{
SPORTS OBJECTS IN CHILDREN'S CULTURE: MATERIAL DIMENSIONS AND \\ REPRESENTATIONS
}

\author{
LOS OBJETOS DEPORTIVOS EN LA CULTURA INFANTIL: DIMENSIONES \\ MATERIALES Y REPRESENTACIONES
}

Pascale Garnier*, Alexandre Moraes de Mello**

\section{Palavras-chave} Jogos e brinquedos. Criança.

Equipamentos esportivos. Características culturais.

Keywords: Games and toys. Child. Sports equipment. Cultural characteristics.

\section{Palabras clave}

Juego y juguetes. Niños. Materiales deportivos. Características Culturales.
Resumo: Os objetos esportivos destinados à criança são parte da cultura material infantil. Colocam em jogo o corpo da criança, com suas reais características físicas, psicológicas, intelectuais e sociais, e as representações de criança pensadas no momento de concepção e produção dos objetos que convêm a cada idade. 0 objetivo deste artigo foi proceder, através de uma pesquisa qualitativa, à análise dos objetos esportivos, considerando a sua materialidade e influência sobre os corpos das crianças, bem como desvendar as formas de significar a infância e o esporte.

Abstract: Sports objects intended for children are part of children's material culture. They put into play the child's body with its actual physical, psychological, intellectual and social characteristics, and representations on the child at the time of the design and production of objects most suitable to each age. The aim of this article was to conduct, through qualitative research, an assessment of sports objects, considering their materiality and influence on children's bodies, and to unveil ways to signify childhood and sports.

Resumen: Los objetos deportivos destinados a los niños forman parte de la cultura material infantil. Ponen en juego el cuerpo del niño, con sus reales características físicas, psicológicas, intelectuales y sociales, y las representaciones del niño pensadas en el momento de la concepción y producción de los objetos adecuados para cada edad. Este artículo presenta, a través de una investigación cualitativa, el análisis de los objetos deportivos, considerando su materialidad e influencia sobre los cuerpos de los niños, y busca desvendar las formas de significar la infancia y el deporte.
*Université Paris 13. Sciences de l'Éducation. Paris, França.

E-mail: pascale.garnier@univ-paris13.fr

**Universidade Federal do Rio de Janeiro. EEFD. Rio de Janeiro, Brasil. E-mail: alexandre@eefd.urr.br

Recebido em: 06-11-2014

Aprovado em: 22-03-2015

(c) (i) (8) Licence Creative Commom 


\section{INTRODUÇÃOO}

O mundo do esporte é, sobretudo, um mundo de objetos. As diversas modalidades demandam materiais específicos para a sua realização. Alguns objetos são indispensáveis a determinadas práticas, como bolas, raquetes e tacos, e outros são complementares. São esses materiais que analisamos aqui, especificamente, os objetos esportivos que são concebidos, produzidos e comercializados para crianças.

O objeto esportivo destinado à criança é um exemplo privilegiado da cultura material infantil que, simultaneamente, coloca em jogo o corpo da criança - com suas reais características físicas, psicológicas, intelectuais e sociais - e as representações de criança que são consideradas no momento de concepção e produção de objetos que convêm a cada idade.

Ao longo da história do esporte, a principal crítica registrada na literatura sobre a prática destinada às crianças relaciona-se aos equívocos cometidos nos treinamentos e competições em idade precoce. As exigências de intensos treinamentos esportivos provocam danos anatômicos e fisiológicos, a busca por resultados em competições esportivas colocam meninos e meninas sob intensa pressão psicológica, causando inúmeros problemas para as crianças (MELLO, 2006).

Entretanto, já nos anos 1960, a condenação de práticas esportivas infantis passou a ser contornada através da adaptação das modalidades, pensadas, então, segundo a idade dos praticantes. $O$ desenvolvimento por federações de práticas esportivas infantis implicou inovações materiais, o que foi uma condição para tornar os esportes acessíveis às crianças mais novas, conservando a especificidade de cada modalidade (GARNIER, 2005; 2006).

Mas, se hoje os esportes são massivamente praticados pelas crianças, como o esporte e equipamentos entram nas suas vidas? Como os objetos se integram ao mesmo tempo às culturas esportivas e às culturas infantis e o que eles causam nas crianças?

Neste artigo, a atenção colocada sobre os objetos esportivos circunscreve a nossa investigação, coloca em evidência aquilo que é da ordem de sua concepção, produção e comercialização, e também o que se refere aos usos efetivos (BROMBERGER; SÉGALEN, 1996). Isto nos leva a "fatiar" o conjunto da "vida social dos objetos" (APPADURAÏ, 1986) e a concentrar sobre o nó onde se cruzam e se cristalizam múltiplos investimentos em jogo, às vezes sobre os objetos que fazem o esporte e às vezes o que eles fazem sobre as crianças.

Para compreender essas hibridações culturais entre o mundo esportivo e o mundo da infância, a análise dos objetos é, portanto, central. Supõe, neste estudo, primeiramente justificar esta centralidade sobre os objetos isoladamente e mostrar as perspectivas teóricas, em termos da análise de uma cultura material infantil. Em seguida, é importante explicitar os caminhos metodológicos que presidem a pesquisa empírica realizada, para depois apresentar os resultados do ponto de vista de uma análise tecnológica e semiótica dos objetos esportivos para as crianças.

Portanto, 0 objetivo deste artigo foi proceder à análise dos objetos esportivos levando ao mesmo tempo em conta a sua materialidade e a sua influência sobre os corpos das crianças, como também desvendar as formas de significar a infância e o esporte. Pretendeu-se, em suma, mostrar a dupla visão de uma cultura material: materialidade engajada dentro da ação e produção de significados sujeita a interpretações. 


\section{BASES TEÓRICAS}

\subsection{Estudos sobre os objetos esportivos: entre materialidade e simbolismo}

Na área do esporte, o interesse teórico pelos objetos tem sido inversamente proporcional ao interesse pelas práticas. Essa ausência de estudos afeta também os objetos destinados às crianças: seria isto porque eles são muito rudimentares ou, inversamente, muito sofisticados? Em todo caso, o mundo esportivo das crianças e o da cultura material infantil carecem de reconhecimento e de visibilidade como matéria de pesquisa.

Os raros estudos sobre os objetos esportivos dizem respeito à utilização pelos adultos. É a materialidade que em primeiro lugar é objeto de pesquisas. A análise de Vigarello (1988) coloca na perspectiva de uma história cultural a evolução dos materiais utilizados dentro dos engenhos esportivos, das formas, das séries de transformações técnicas que se imbricam, de lógicas motoras e lógicas instrumentais e, de outra maneira, inovações materiais, tecnológicas e científicas. Aliás, na medida em que se regulamenta uma modalidade esportiva, a inovação técnica não se dá sem conflito, como aponta a análise de Defrance (1985) consagrada à adoção da vara de fibra de vidro no atletismo.

A análise das transformações dos objetos reconduziu a novas formas de engajamento motor dentro das práticas e, do mesmo modo, seus princípios de percepção e de apreciação. É o que mostra particularmente, com respeito a assumir riscos no esporte, o estudo sobre os instrumentos de alpinismo elaborado por Duez (2009). É o "corpo sensível" que pode ser colocado em primeiro plano de um emaranhado entre o material de esporte e a experiência corporal (LEVEL; LESAGE, 2012). O objeto esportivo não tem senão o sentido de integração dentro das "condutas motoras", para retomar aqui o termo de Parlebas (1967) designando a totalidade das dimensões, ao mesmo tempo, sensório-motora, afetiva, social e significante de toda a motricidade.

Uma segunda via de análise dos objetos esportivos foi mais recentemente aberta a favor das transformações econômicas e culturais do mundo esportivo: a dos objetos de consumo de massa tornados marcas identitárias, individuais e coletivas (OHL, 2003). Não mais fechados dentro dos estádios e dos ginásios, os objetos invadem os espaços e os tempos cotidianos e se cristalizam na midiatização das apresentações e narrações esportivas. Através dessa perspectiva, parece que a materialidade dos objetos perde sua dimensão, até ser "aligeirado" sob a forma de palavras, de imagens ou taxonomias (DAGOGNET, 1996). O objeto se torna signo, suporte para produção das aparências, superfície onde se inscreveu uma partilha de emoções e de identificações suscitadas pelo esporte.

Essa materialidade se apaga também quando os objetos esportivos são mostrados como temas de conversas entre praticantes, relíquias que marcam as biografias individuais ou ainda o patrimônio dos museus de esporte. Resta esta ideia fundamental de uma exploração econômica e simbólica do esporte que propulsiona estes objetos de consumo à posição dos analisadores das categorias da cultura e das mutações do simbólico (DOUGLAS; ISHERWOOD, 2008). Todo o interesse da abordagem antropológica dos bens de consumo que propõem Douglas e Isherwood vem do vínculo estreito que essa abordagem tece entre julgamentos morais, categorias cognitivas e objetos. É através dos objetos que uma cultura 
é concretizada, adquire estabilidade e consistência, tornando-se visível e convincente. Ao mesmo tempo, os objetos aparecem como "marcadores", definindo a identidade dos indivíduos que têm de imediato uma dimensão moral, mostrando, através deles, o que convém e como é necessário tratá-los. Centrada sobre a dimensão simbólica dos objetos, essa abordagem passa deliberadamente à margem de sua materialidade e de sua função prática. Da mesma forma que a análise de Baudrillard (1968) cai sob o golpe da crítica de um "semiotismo", que reduziu os objetos aos signos em detrimento de sua materialidade e de seu compromisso com a ação (JULIEN; WARNIER, 1999; JULIEN; ROSSELIN, 2005).

Para ultrapassar essa alternativa entre as análises de tipo tecnológico e semiológico dos objetos, importa trabalhar na direção de uma "semio-tecnologia" dos objetos, para retomar aqui o termo de Bromberger (1979). O problema não é escolher entre a materialidade da cultura e seu simbolismo ou, dito de outra maneira, entre uma "inteligência das situações, onde a ação e as coisas se fundem" e uma "inteligência que opera sobre as representações e os símbolos" (WALLON, 1970, p. 95). A verdadeira questão é a de um posicionamento teórico que permita pensar sua articulação, de compreender suas interfaces, ver seus conflitos.

\subsection{0 objeto "convida" à ação}

No coração de relações teóricas complexas entre o corpo e os objetos (DIASSIO, 2009), a compreensão dos objetos do mundo esportivo pode ser facilitada a partir de um posicionamento fenomenológico: "mover seu corpo é visar através dele às coisas, é deixá-lo responder à solicitação que se exerce sobre ele sem nenhuma representação" (MERLEAUPONTY, 1978, p. 161). É considerar o objeto como um convite a agir, um "polo de atos virtuais": "o objeto percebido é imediatamente codificado como um conjunto determinado de hipóteses de ações" (RIZZOLATTI; SINIGAGLIA, 2008, p. 60). É nos convidar a pensar os objetos como "objetos que são feitos para...", o que significa - ao menos potencialmente - objetos engajados na ação.

Sem dúvida, somente a análise dos usos efetivos dos objetos permite delimitar as significações múltiplas possíveis. Ao mesmo tempo, essa análise dos usos supõe uma qualificação prévia dos objetos. Estudar, por exemplo, a produção social das identidades sexuais através de uma cultura material, é pressupor a existência de objetos a priori diferentes segundo o gênero, mesmo que eles permitam diferentes reinterpretações, usos desviados e mesmo invertidos (ANSTETT; GÉLARD, 2012).

Da mesma maneira que o gênero, a cultura material concretiza a priori as diferenças de idade, distinguindo particularmente os objetos "para crianças" e "para adultos", entre a imprecisão e o rigor da classificação de idades (GARNIER, 2006). Essa compreensão dos objetos não é da ordem dos atributos que lhes são intrínsecos; é sempre situada nos repertórios da ação, ao "fazer com", endereçados aos destinatários diferentes ou semelhantes. Para Merleau-Ponty, essa ação de solicitação dos objetos se relaciona à maneira pela qual, num "mundo cultural", afirma ele, "cada objeto carrega subjacente a marca da ação humana à qual serve" (MERLEAU-PONTY, 1978, p. 162). Nesse sentido, o objeto pode ser pensado como algo que oferece apoio à atividade das crianças, diante de suas possibilidades de ação sobre ele, como afirma Gibson (1986), ao mesmo tempo em que o objeto exerce sobre as crianças a sua influência. 


\subsection{Objetos para adultos, objetos para crianças}

Duas perspectivas de análise dos objetos esportivos para os adultos, uma calçada sobre a materialidade, a outra, sobre a dimensão simbólica, fazem eco a uma dupla orientação dos trabalhos sociológicos sobre a infância: uma se interessando pela produção para crianças de dispositivos adaptados ou híbridos implicando os corpos (PROUT, 2000); a outra centrada sobre a noção de "reprodução interpretativa" (CORSARO, 2005), através da qual as crianças se apropriam da cultura dos adultos atribuindo-lhe suas próprias significações.

Uma e outra, na nossa percepção, são indispensáveis para pensar as culturas materiais e, mais particularmente, para estudar as operações que permitem considerar os objetos esportivos como fatores voltados especificamente à criança e à maneira pela qual ela é influenciada pelos seus objetos. Essas operações são necessariamente duplas, inscritas, por sua vez, dentro da materialidade dos objetos e dos corpos, e no interior da interpretação das representações do que significa uma atividade física, lúdica e/ou esportiva para as crianças.

Assim, os objetos não são simplesmente destinados como externos às crianças, eles as integram como que indiretamente, dentro de sua materialidade e do conjunto das representações que especificam. Não se limitam a veicular imagens ou definições preconcebidas de infância. Mais radicalmente, desafiam e atualizam o que são as crianças e o que convém para elas. Não mais o objeto pressupõe fazer fundo para as competências motoras e interpretativas da criança, porque ao mesmo tempo o objeto as institui, contribuindo para produzi-las.

Por outro lado, pensar os objetos esportivos para as crianças obriga a redobrar a seriedade com o produto técnico, seu objetivo de eficácia, pela frivolidade e fantasia do jogo através da mudança do quadro que ele opera (BROUGÈRE, 2005). Mas, se "com o jogo, atentamos para os limites do dispositivo de extração das propriedades dos objetos" (THÉVENOT, 1993, p.98), é precisamente sua plasticidade, esta abertura variável dos objetos às interpretações, que impede traçar fronteiras bem definidas entre brinquedos e material de esporte.

\section{DECISÕES METODOLÓGICAS}

\subsection{Produção e análise de um corpus}

Cada material esportivo infantil pode se apresentar como uma construção formada de diversos elementos e utilizando diferentes referenciais, uns ancorados nos próprios universos esportivos, outros em torno do universo do brincar e da infância, em que competências motoras e interpretativas podem estar em interferências e em tensões. Diante disto, para 0 desenvolvimento deste estudo foi necessário produzir um corpus constituído de diferentes séries de objetos, a partir da análise reflexiva e categorização dos objetos, segundo diferentes "famílias" organizadas segundo a tipicidade e a possibilidade de substituição entre objetos de um mesmo tipo (HOUDÉ, 1992).

Para a constituição do corpus, foi realizado um levantamento dos objetos em 18 sites da internet, sendo seis de empresas de esporte, nove de empresas de brinquedos e jogos e três de comparação de preços. A título de controle e para melhor análise dos objetos, foram 
realizadas seis visitas de observação técnica às empresas que comercializam fisicamente os mesmos objetos identificados nos sites: duas lojas integrantes de grandes redes de material de esportes, três grandes lojas de brinquedos e um hipermercado.

Foram organizadas 12 séries de objetos, cujos universos de referência são aqueles das modalidades esportivas mais ou menos midiatizadas e institucionalizadas, e aqueles dos brinquedos tradicionais infantis: velocípede, patinete, trampolim, cavalinho de madeira, frisbee, futebol de botão, corda de saltar, bicicleta e outros. No conjunto, a pesquisa abrangeu o total de 225 objetos.

A metodologia qualitativa e comparativa de análise ocorreu através de interações sucessivas entre a construção de categorias de codificação e a produção do corpus dos objetos, seguindo um processo de comparação contínua e exaustiva de dados qualitativos (GLAZER; STRAUSS, 2010).

Complementaram os caminhos metodológicos a realização de dez entrevistas com pais de crianças de cinco a seis anos e nove entrevistas coletivas com trios de crianças dessa mesma idade, abordando escolhas e usos de objetos esportivos.

\section{ANÁLISE E DISCUSSÃO DOS RESULTADOS}

\subsection{Entre os universos esportivos e a infância, entre as dimensões do objeto e 0 crescimento e desenvolvimento da criança}

Inicialmente, apresentamos as variações tecnológicas e, em seguida, as combinações interpretativas que são emprestadas aos objetos, considerando os cruzamentos entre esses dois quadros de análise que requerem a compreensão da singularidade de cada objeto.

Para tomar como exemplo, uma pequena bicicleta "vestida" de zebra (figura 1) opera a síntese entre uma adaptação de bicicleta para crianças pequenas e sua metamorfose lúdica em animal: objeto para pedalar, mas também para mergulhar dentro do universo narrativo. Mas se, em comparação, uma raquete de "minitênis" (figura 2) parece ser um objeto despojado, ela convida tanto quanto a bicicleta a outras histórias e ações. Esses dois objetos ilustram esse cruzamento a cada aspecto original entre a materialidade do objeto e os universos de sentidos dentro do qual se inscrevem, definindo assim o que convém à criança e ao mesmo tempo "autodefinindo-se".

Figura 1 - Bicicleta-zebra

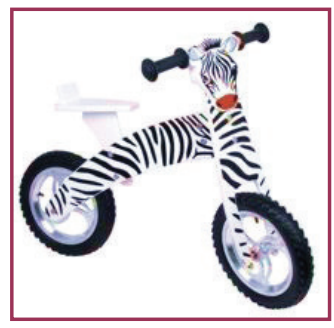

Figura 2 - Raquete de minitênis

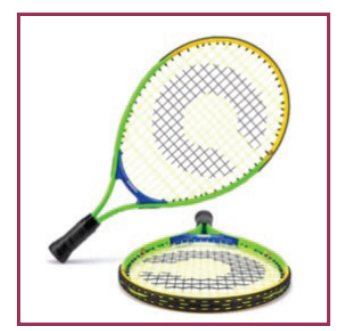

Figura 3 - Carrinho de golfe

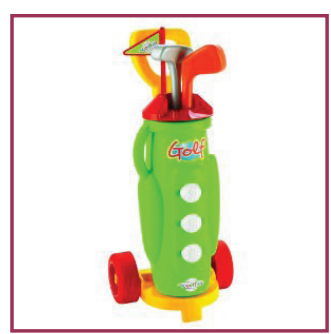

Figura 4 - Frisbee Disney

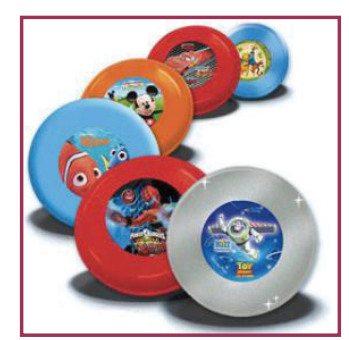

Fonte: Fotografias de autoria de Pascale Garnier 
O tamanho dos objetos, ou mais exatamente uma proporcionalidade entre as características físicas dos objetos (tamanho, peso, volume) e aquelas das crianças é a primeira forma de ajustamento de grandeza, distanciando as crianças menores das maiores. Trata-se aqui da primeira diferença a ser observada, primeira das representações do que convém à criança, primeira em se tratando de colocar o objeto ao alcance dos pequenos. Os objetos são ordenados segundo seu tamanho ou permitem regulagens de altura à medida que a criança cresce, como o selim da bicicleta (figura1). De fato, o tamanho e o peso das crianças abrem um espaço de cálculos entre sua idade, definida em número de anos civis, e as dimensões dos objetos, no sentido da medida tanto normativa quanto descritiva.

As remodelações sucessivas dos objetos no seio de uma mesma série retratam um desenvolvimento da criança, eles ocorrem seja por simplificação de um tipo de objeto, por exemplo, retirando pedal e freio de uma bicicleta (figura 1), seja pelo aumento da complexidade. Com duas, três ou quatro rodas, a patinete ilustra bem o que fazer cada vez mais cedo, dando às crianças um suporte biomecânico à medida de seu equilíbrio e de suas forças: apoios múltiplos, superfícies ampliadas ou braços de alavancas reduzidas.

Neste sentido, a raquete de "minitênis" (figura 2) não é uma raquete em miniatura, mas um dispositivo específico: cabo mais curto, cabeça da raquete ampliada e encordoamento flexível. Toda uma orientação do movimento pode ser igualmente integrada dentro do objeto: referências visuais e redução do grau de liberdade, por exemplo, o que predetermina a motricidade das crianças. A orientação pode ser "negativa", criando obstáculos para evitar um uso desviante, ou "de iniciação" procurando favorecer certos movimentos (DODIER, 1993). Destinado às crianças, o objeto põe em prática muito especialmente certa "tolerância": permite superar certas dificuldades ou minimizar as consequências dessas dificuldades.

Mesmo a vigilância dos adultos sendo indispensável, a segurança da criança é primeiramente delegada aos objetos através de normas que devem respeitar: materiais (em espumas, plásticos e tecidos), formas arredondadas, ou ainda elementos de proteção integrados. Ocorre às vezes de o objeto possuir um apoio para o adulto, como um suporte em forma de bastão que pode ser acoplado para empurrar velocípedes e que permite as forças dos maiores serem revezadas com as dos pequenos. Claramente observado, esse apoio para 0 adulto sinaliza que se o objeto é bom "para" a criança, é ao mesmo tempo endereçado aos pais.

Por outro lado, graças aos elementos integrados e à elasticidade dos materiais, o objeto é criado com potencialidades a explorar a favor de um domínio futuro, ele pode responder às solicitações que demanda, por exemplo, o uso acrobático. Como uma prancha na qual é necessário descobrir a flexibilidade debaixo da rigidez em primeiro plano, o objeto autoriza então um salto para a motricidade futura; ele reserva o poder de futuro à medida que ocorre um desenvolvimento potencial das competências da criança.

Outra característica frequente dos objetos para as crianças é a sua polivalência, que autoriza um duplo uso, como as raquetes podem servir tanto ao tênis quanto ao badminton, significados respectivamente pela bola e peteca vendidos conjuntamente numa só embalagem. Essa polivalência pode ser ainda obtida graças a vários objetos vendidos em conjunto, como kits, juntando uma bola, um par de raquetes e um frisbee, oferecendo uma amostra que permite à criança "experimentar" diferentes esportes, antes de fazer a escolha de uma modalidade esportiva em particular. 


\subsection{Os objetos e a iniciação esportiva}

Através de múltiplos ajustamentos, se coloca uma tensão entre os limites e as competências motoras das crianças. Há forte tensão entre colocar-se em risco e a segurança, entre o que o objeto autoriza e o que é proibido fazer com ele, entre forças e dificuldades dos pequenos. Assim, nos objetos infantis que integram as bolsas de golfe em plástico (figura 3) os choques e as pancadas são às vezes previstos e amortecidos; 0 objeto pode, então, ser colocado em todas as mãos, mas em contrapartida não oferece apoio para a realização de trajetórias precisas e longas. Ou seja, há a tensão entre presente e futuro: o que torna possível uma motricidade atual pode se revelar um freio para o progresso futuro.

Em graus variados, os objetos são todos de compromissos frágeis, por um lado um material para movimentar, despender energia e distrair, de outra parte, matéria de um "corpo a corpo" exigente em que, ao mesmo tempo em que é agarrado, "O objeto agarra o corpo" (BESSY; CHATEAURAYNAUD, 1995, p. 273).

É precisamente neste ponto, aquele de influência do objeto sobre a criança, que se abre 0 espaço próprio para a iniciação em uma modalidade esportiva, seja ela realizada em um clube esportivo, numa escola ou numa comunidade de praticantes com um grupo de pares. Mesmo que não se trate aqui de uma iniciação ritual (ZEMPLÉNI, 2007), todo processo de iniciação marca o corpo, imprimindo traços duráveis. Em efeito, se a iniciação não é obrigatoriamente sinônimo de prova corporal dolorosa (chutes, golpes, machucados, etc.), ela segue a par com as aprendizagens que se ancoram nos vincos que se formam entre coisas e corpo. Merleau-Ponty $(1978$, p. 168) refere-se a esta capacidade de incorporação dos objetos: "se habituar a um chapéu, a um automóvel ou a um bastão, é se instalar neles, ou inversamente os fazer participar da 'voluminosidade' do próprio corpo. 0 hábito exprime 0 poder que nós temos de dilatar nosso ser ao mundo ou de mudar de existência em nós, anexando novos instrumentos".

A iniciação esportiva, pela sua transitividade e sua autorreferência, pede um espaço e um tempo separados que fazem uma ruptura com os apegos domésticos da criança. Se os pais são primeiros vetores de uma iniciação esportiva, essa iniciação pede por princípio um espaço especializado, um mundo que é próprio, mais do que aquele da família. A iniciação é igualmente o princípio de uma motricidade "extra"-ordinária que tem validade e valor dentro do círculo dos iniciados, amadores e praticantes de uma modalidade esportiva particular.

Com a iniciação, se abre outra ordem de grandeza tal qual aquela da idade: a que conduz 0 "debutante", o noviço, ao "expert", ao "campeão". Nessa nova situação, surge a aspiração ao "alto nível" esportivo, solicitando uma "subida na escala" do material - em qualidade e em custo financeiro -, ou seja, de novos investimentos que são ao mesmo tempo econômicos, sociais e afetivos, no sentido de apegos e de emoções que podem se renovar periodicamente.

Por outro lado, as atividades prazerosas de iniciação e o uso de materiais motivadores são determinantes para o estabelecimento de vínculos duradouros com determinada modalidade esportiva (MELLO, 2000, 2001).

\subsection{Influências e interpretações dos universos esportivos}

Os objetos mergulham as crianças em diferentes universos culturais, dentro dos quais se inscrevem o tipo do objeto e a motricidade que ele pode materializar. Os objetos significam e 
compõem esses universos, formando, progressivamente, as coleções ou as narrativas relativas aos eventos ou situações, numa forma de categorização ancorada na experiência privilegiada pela criança (HOUDÉ, 1994). Assim, por exemplo, a cesta do basquete pede uma bola de basquete, mas também calçados particulares, um look de vestimentas, de equipamentos, à semelhança da NBA, seus campeões e seus produtos derivados, enfim, todo um universo do basquetebol.

A lista de objetos segue uma progressão geométrica segundo as modalidades esportivas, à medida de suas imbricações específicas com o mundo que vende (o "mercado") e sua midiatização. Cada modalidade representa assim um universo próprio, com sua autorreferencialidade, no qual os equipamentos são todos, por sua vez, símbolo, ícone e indício. Essa integração dos objetos aos universos esportivos é mais frequentemente intensificada pelas marcas, logotipos, palavras, imagens associadas aos objetos, como é o caso da raquete de tênis. Apropriando-se do objeto, a criança toma parte de um universo esportivo particular. Assim, ela não brinca mais somente "com" uma raquete de tênis, ela "joga tênis". Através de sua raquete, ela foi colocada dentro do universo do tênis e se familiariza com sua motricidade, seu léxico, seus códigos, suas normas e seus valores; ela se torna um "jogador de tênis", personagem desse universo. E, mesmo que a raquete que a criança tem na mão não dê materialidade a uma motricidade à altura de uma "verdadeira" atividade tenística, esse objeto pode, todavia, dar apoio às suas operações interpretativas, tornar-se coadjuvante indispensável às epopeias esportivas.

O que pode ser considerado pejorativamente pelo adulto como "brinquedo", material de "faz de conta", ou "simulacro" do material de esporte, permite o exercício destas competências interpretativas infantis. Supõe chaves de leitura dos objetos; leitura, tanto no sentido próprio como no sentido figurado, quando o objeto é muito expressamente marcado, decorado e realçado pela palavra designando uma modalidade esportiva, como o carrinho de tacos de golfe em plástico, onde está inscrita a palavra golf (figura 3). Quanto mais um objeto esportivo se pareça com uma imitação do objeto "oficial", mais ele tem a chance de ser marcado, etiquetado, como se o fraco apoio dado ao engajamento numa motricidade esportiva pudesse ser compensado por sua apropriação simbólica: para a criança, brincar de jogar golfe é jogar golfe.

Ao mesmo tempo em que as lojas de esporte estendem sua oferta para as crianças cada vez mais novas, as seções das lojas de brinquedos se enchem de imitações mais ou menos realistas de equipamentos de esportes que, assim como vasilhas de cozinha em miniatura e pequenos carros, participam da onipresença do fato esportivo no mundo que é colocado para a vivência das crianças.

\subsection{Os objetos e o universo da infância}

Os objetos remetem igualmente a uma cultura infantil de massa que, como para a cultura esportiva, representa os "universos imersos" e as "lógicas transmidiáticas", em particular através das licenças de produtos (BROUGÈRE, 2008). Alguns objetos esportivos são marcados e colonizados pelos personagens que circulam de um suporte a outro: bolas, raquetes, patinetes, etc. Como os frisbees sob licença Disney (figura 4) e outros objetos esportivos com personagens estampados, como o Homem-Aranha ou Hello Kitty, que, mesmo 
deslocados do universo do esporte, estão onipresentes na vida de meninos e meninas. Através da diversidade dos personagens, das cores e dos acessórios (estampados num cesto de boneca para bicicleta, por exemplo), são massivamente significados de diferenças de gênero para um mesmo tipo de objeto ou, ainda, marcam os diferentes tipos de objetos.

Por essas combinações semióticas, o objeto se integra dentro de narrativas, convida a brincadeiras que podem relativizar a implicação motora ou fazê-la perder seu caráter autorreferencial como, por exemplo, fazer sua boneca andar de bicicleta ao brincar de faz de conta. Os objetos tornam-se, assim, divertidos, eles permitem passar à margem da seriedade de um compromisso esportivo, de desviar dele sem se opor frontalmente e sinalizam em direção a um mundo próprio das crianças, povoado de materiais que, manifestadamente, são para eles e, do ponto de vista delas, são também "para nós". Com marcas e desenhos estampados, os objetos esportivos mudam de quadro e, retomados como brincadeira, se colocam à altura dos pequenos e permitem a eles dominar e se familiarizar de forma suave com os universos esportivos.

Essa produção dos objetos com suas marcas, em particular pelas licenças de uma cultura de massa infantil, carrega igualmente fortes diferenciações segundo a idade. Com efeito, isto tende a se eliminar à medida que o objeto e a criança crescem, como se houvesse aí uma sucessão de atividades interpretativas, depois motoras. Com o avançar da idade, tudo isto parece deixar lugar ao anonimato em função dos mecanismos do esporte que reivindica a competição esportiva.

Mas, além das marcações citadas, o objeto para os pequenos pode também passar por uma metamorfose, tornando-se muito frequentemente um animal (figura 1), próximo dos universos da infância.

A distração esperada dos objetos, essa maneira descontraída de se conectar às coisas (ASSOULY, 2006), se nota pelos acessórios que lhes são associados: toque sonoro, música, luzes brilhantes, etc. Em princípio, objetos animados por mecânicas a molas ou dispositivos eletrônicos, mas também invenções lúdicas realizadas por hibridação entre tipos de objetos. Existe aí outro critério que se opõe aos objetos convencionais das modalidades esportivas: a do divertimento (fun), a pesquisa de sensações misturando prazer, surpresa, subversão. Pode ser nesta ausência de limites e neste ecletismo que se exprimem novos esportes de amanhã. Em todo caso, eles dão a medida de uma aposta em lazer através do esporte, por oposição ao mundo da competição institucionalizada. É no interior dessas invenções lúdicas que encontramos também os objetos que, em casa, podem ser partilhados pelos grandes e pequenos.

\section{CONCLUSÃO}

É necessário sublinhar que os objetos não se limitam a marcar as diferenças de idade entre os pequenos e os grandes. Enquanto atendem à criança, eles podem estar investidos de um futuro potencial e de um potencial de futuro. Crescimento e desenvolvimento da criança, mas também crescimento em direção ao "alto nível" esportivo são marcados pelos objetos, segundo diferentes níveis esportivos e regulamentos.

Assim, podemos distinguir quatro maneiras diferentes de colocar os objetos esportivos à disposição das crianças: uma produção de um material especificamente concebido para uma iniciação esportiva precoce (figura 2); a colocação como brinquedo de um material 
esportivo, suporte para a simulação lúdica dos mais novos (figura 3); o conjunto de objetos com características associadas a uma cultura infantil de massa, notadamente através de licenciamento do produto (figura 4); ou ainda as invenções decididamente destinadas à diversão (figura 1), mesmo fora das convenções esportivas.

Os objetos permitem, assim, delinear a representação de diferentes infâncias: umas em torno do futuro, através da imitação de um mundo esportivo adulto; outras, atualizando as autênticas competências esportivas das crianças; e algumas valorizando a cultura infantil de massa ou reatualizando o patrimônio tradicional para uma infância de hoje.

Neste sentido, complementamos a nossa análise pontuando as implicações das diferenças socioeconômicas no seio das famílias que são, a princípio, consumidoras de objetos mais ou menos carregados de inovações tecnológicas, mais ou menos marcados por uma cultura infantil de massa. Essas famílias têm uma preocupação com um design apurado e com o que podem financeiramente oferecer às crianças.

Portanto, os objetos são indispensáveis para se tornar tangíveis às competências motoras das crianças, ligados ao seu engajamento na ação e suas competências interpretativas ligadas às representações daquilo que é às vezes "esportivo" ou possui "características próprias". Insistimos aqui sobre a ausência de fronteira rígida que distinguiria, de um lado, o "verdadeiro" material de esporte e, de outro, os jogos e os brinquedos. Parece, ao contrário, que a oferta de produtos joga deliberadamente sobre as fronteiras imprecisas e ambivalentes entre a seriedade dos esportes e a diversão das culturas lúdicas. Essa distinção pode então fazer-se objeto de debates e negociações, tanto entre adultos como entre crianças (GARNIER, 2013).

Articulando estreitamente a análise tecnológica e a semiológica, um princípio pragmático demonstra a rica abundância dos objetos que permeiam nossa vida cotidiana, constituindo um observatório privilegiado de esclarecimento e de recomposição de nossos universos culturais, como a nossa maneira de agir com as crianças. Quando, nos tempos recentes, a bola e o skate tornam-se objetos digitais e a interface de um captador de movimento ocupa o lugar de uma raquete, este posicionamento teórico parece tanto quanto mais necessário no que se relaciona à compreensão de como as transformações tecnológicas e simbólicas de objetos abrem múltiplas possibilidades corporais.

Portanto, o estudo da relação entre as abordagens tecnológicas e corporais da cultura material e as suas dimensões simbólicas e narrativas nos permite compreender a extensão e a renovação constante das práticas lúdicas e esportivas, especialmente as relacionadas às crianças.

\section{REFERÊNCIAS}

ANSTETT, Élisabeth; GÉLARD, Marie-Luce. Les objets ont-il un genre? culture matérielle et production sociale des identités sexuées. Paris: A. Colin, 2012.

APPADURAÏ, Arjun. The social life of things: commodities in cultural perspective. Cambridge: Cambridge University, 1986. 
ASSOULY, Olivier. Le design comme esthétique de la réception. In: FLAMAND, B. (Ed.). Le design: essai sur des théories et des pratiques. Paris: Editions du Regard, 2006. p. 259-276.

BAUDRILLARD, Jean. Le système des objets. Paris: Gallimard, 1968.

BESSY, Christian; CHATEAURAYNAUD, Francis. Experts et faussaires: pour une sociologie de la perception. Paris: Métailié, 1995.

BROMBERGER, Christian. Technologie et analyse sémantique des objets: pour une sémiotechnologie. L'homme, Paris, v. 19, n. 1, p. 105-140, janv./mars 1979.

BROMBERGER, Christian; SÉGALEN, Martine. L'objet moderne: de la production sérielle à la diversité des usages. Ethnologie française, Paris, v. 26, n. 1, p. 5-16, 1996.

BROUGÈRE, Gilles. Jouer/apprendre. Paris: Economica, 2005.

BROUGÈRE, Gilles (Ed.). La ronde des jeux et des jouets. Paris: Autrement, 2008.

CORSARO, William Arnold. The sociology of childhood. Thousand Oak: Pine Forge, 2005.

DAGOGNET, François. Les dieux sont dans la cuisine: philosophie des objets et objets de la philosophie. Tours: Synthelabo, 1996.

DEFRANCE, Jacques. L'adoption de la perche en fibre de verre. Culture technique, Paris, 13, p. 257-263, 1985.

DIASIO, Nicoletta. La liaison tumultueuse des choses et des corps: un positionnement théorique. In: JULIEN, M.P.; ROSSELIN, C. (Ed.). Le sujet contre les objets... tout contre: ethnographies de cultures matérielles. Paris: CTHS, 2009. p. 21-83.

DODIER, Nicolas. Les arènes des habiletés techniques. Raisons Pratiques, Paris, n. 4, p. 115139, 1993.

DOUGLAS, Mary; ISHERWOOD, Baron. Pour une anthropologie de la consommation: le monde des biens. Paris: Edition du regard, 2008.

DUEZ, Jean-Baptiste. Les instruments de l'alpiniste. Techniques et Culture, Paris, 52-33, p. 330-351, 2009.

GARNIER, Pascale. Le développement des pratiques sportives des plus jeunes, Eléments pour une histoire comparative en France. Sport History Review, Ontario, v. 36, n. 1, p. 3-20, 2005.

GARNIER, Pascale. L'enfant et le sport: classements d'âge et pratiques sportives. In: SIROTA, R. (Dir.). Eléments pour une sociologie de l'enfance. Rennes: PUR, 2006. p. 205-214.

GARNIER, Pascale. Childhood as a question of critiques and justifications: Insight into Boltanski's Sociology. Disponível em: <http://chd.sagepub.com/content/early/ 2013/07/02/0907568213491770>. Acesso em: 1ํ. jun. 2013.

GIBSON, James Jerome. The ecological approach to visual perception. New Jersey: Lawrence Erlbaum, 1986.

GLAZER, Barney; STRAUSS, Anselm. La découverte de la théorie ancrée: stratégie pour la recherche qualitative. Paris: Colin, 2010. 
HOUDE, Olivier. Catégorisation et développement cognitif. Paris: PUF, 1994.

JULIEN, Marie-Pierre; ROSSELIN, Céline. La culture matérielle. Paris: La Découverte, 2005.

JULIEN, Marie-Pierre; WARNIER, Jean-Pierre. (Ed.). Approches de la culture matérielle: corps à corps avec l'objet. Paris: L'Harmattan, 1999.

LEVEL, Marie; LESAGE, Thierry. Objets sportifs et corps sensibles: entre cultures matérielles et expériences corporelles. Staps, Paris, n. 98, p. 23-38, 2012.

MELLO, Alexandre Moraes. Jogos e brincadeiras como estratégias metodológicas de ensino na iniciação esportiva. In: CONGRESSO LATINO-AMERICANO FIEP-UNIMEP, 1, 2000, Piracicaba. Coletâneas. Piracicaba: UNIMEP, 2000. p.146-149.

MELLO, Alexandre Moraes. O brincar na iniciação esportiva: por uma participação infantil de qualidade e sem exclusão. In: CONFERÊNCIA NACIONAL DE EDUCAÇÃO, CULTURA E DESPORTO, 1., 2001, Brasília. Desafios para o Século XXI. Brasília: Câmara dos Deputados, 2001. p. 667-670.

MELLO, Alexandre Moraes. Psicomotricidade, educação física e jogos infantis. 6. ed. São Paulo: Ibrasa, 2006.

MERLEAU-PONTY, Maurice. Phénoménologie de la perception. Paris: Gallimard, 1978.

OHL, Fabien. Les objets sportifs: comment des biens banalisés peuvent constituer des référents identitaires. Anthropologie et sociétés, Québec, v. 27, n. 2, p.167-184, 2003.

PARLEBAS, Pierre. Une pédagogie des conduites motrices. Revue EPS, Paris, n. 88, p. 17-23, 1967.

PROUT, Alan. (Ed.) The body, childhood and society. London: Macmillan, 2000.

RIZZOLATTI, Giacomo; SINIGAGLIA, Corrado. Les neurones miroirs. Paris: Jacob, 2008.

THÉVENOT, Laurent. Essai sur les objets usuels. Raisons Pratiques, Paris, n. 4, p. 85-111, 1993.

VIGARELLO, Georges. Techniques d'hier et d'aujourd'hui: une histoire culturelle du sport. Paris: EPS-R. Laffont, 1988.

WALLON, Henri. De l'acte à la pensée. Paris: Flammarion, 1970.

ZEMPLÉNI, András. Initiation. In: BONTE, P.; IZARD, M. (Dir.). Dictionnaire de l'ethnologie et de l'anthropologie. Paris: PUF, 2007. p. 375-377. 